\title{
PRELÚDIO DO PAISAGISMO MODERNO NO BRASIL
}

Guilherme Mazza Dourado

Arquiteto e pesquisador, mestre pela Escola de Engenharia de São Carlos da USP

É co-autor do volume Oswaldo Arthur Bratke (São Paulo: Pró-Editores, 1997), e organizador do livro Visões de paisagem (São Paulo: ABAP, 1997)

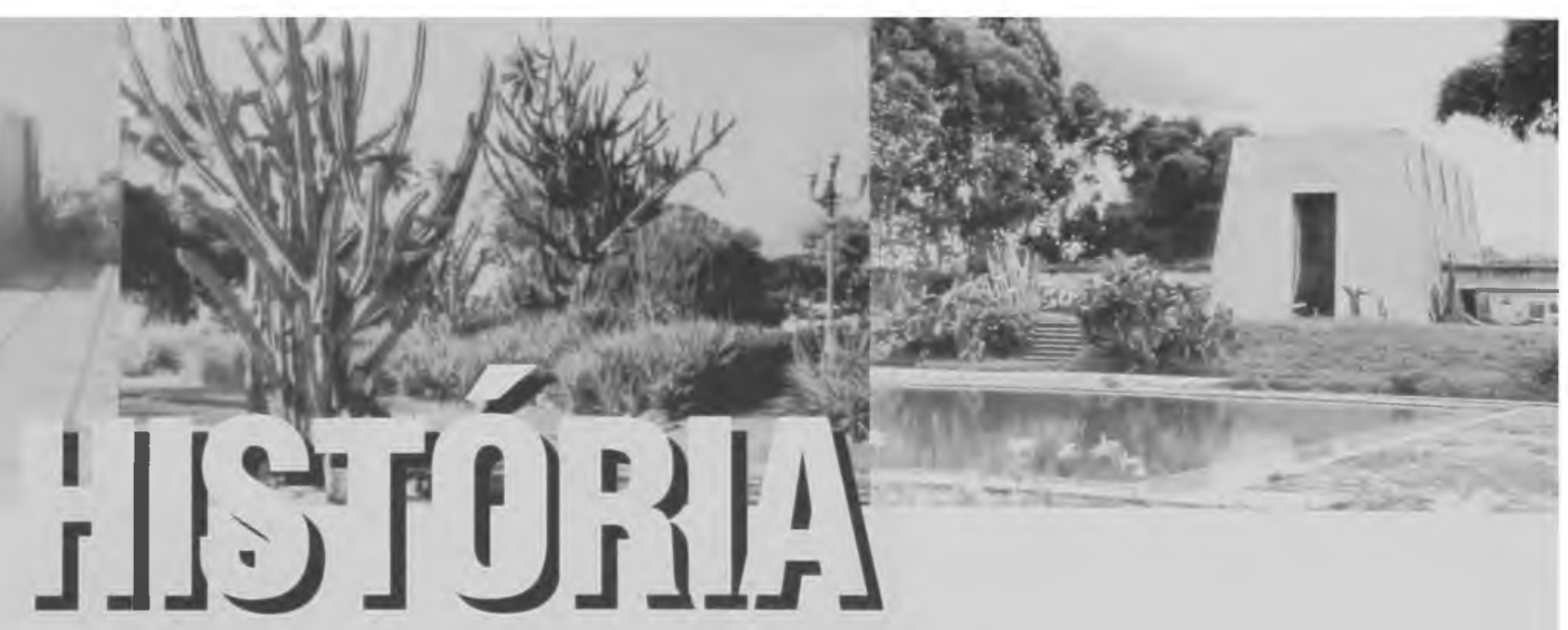




\section{RESUMO}

O texto investiga o nascimento do paisagismo moderno no Brasil, entre os anos 20 e 30, como um fenômeno que migra progressivamente da esfera privada para a pública. Destaca o papel de duas figuras centrais: Mina Klabin Warchavchik, com seus jardins residenciais em São Paulo, e Roberto Burle Marx à frente do programa de renovação das praças do Recife.

\section{ABSTRACT}

This work reviews the early stage of modern landscape in Brazil during the twenties and thirties as a fact that moves from private to public range. It focuses on two main figures: Mina Klabin Warchavchik and Roberto Burle Marx, who headed the renewal program of Recife's squares. 


\section{PRELÚDIO DO PAISAGISMO MODERNO NO BRASIL}

A criação do paisagismo moderno no Brasil foi indissociável da própria consolidação da arquitetura moderna no país. Entre o final dos anos 20 e a década de 30 , nossos arquitetos modernos estavam imbuídos cada vez mais da disposição de pensar uma nova arquitetura que não apenas agregasse as possibilidades da planta livre, dos suportes construtivos e tecnológicos mais avançados, mas que enfatizasse a criação de um lugar, como expressão das especificidades brasileiras.

$E$, nesse sentido, não tardaram a perceber o quão importante poderiam ser as práticas paisagísticas associadas ao projeto de arquitetura. Ao se rasgar cada vez mais as plantas para os exteriores, ao se buscar interagir com o que havia para além dos interiores, tornou-se inevitável o reconhecimento das paisagens e a valorização dos entornos e espaços abertos projetados.

Por certo, Lúcio Costa foi um dos primeiros arquitetos modernos que se mostrou sensível à necessidade de repensar a caracterização dos espaços abertos, a partir de uma série de residências desenhadas ao longo dos anos 30 , que não chegaram a sair do papel.

Desse momento em diante, em várias regiões do Brasil, ampliou-se o contingente de arquitetos dedicados em maior ou menor grau à consolidação de um paisagismo de teor moderno, em paralelo à atuação em arquitetura. Entre eles estava Flávio de Carvalho e Rino Levi, em São Paulo; Attilio Correa Lima e Francisco Bolonha, no Rio de Janeiro; e vários outros.

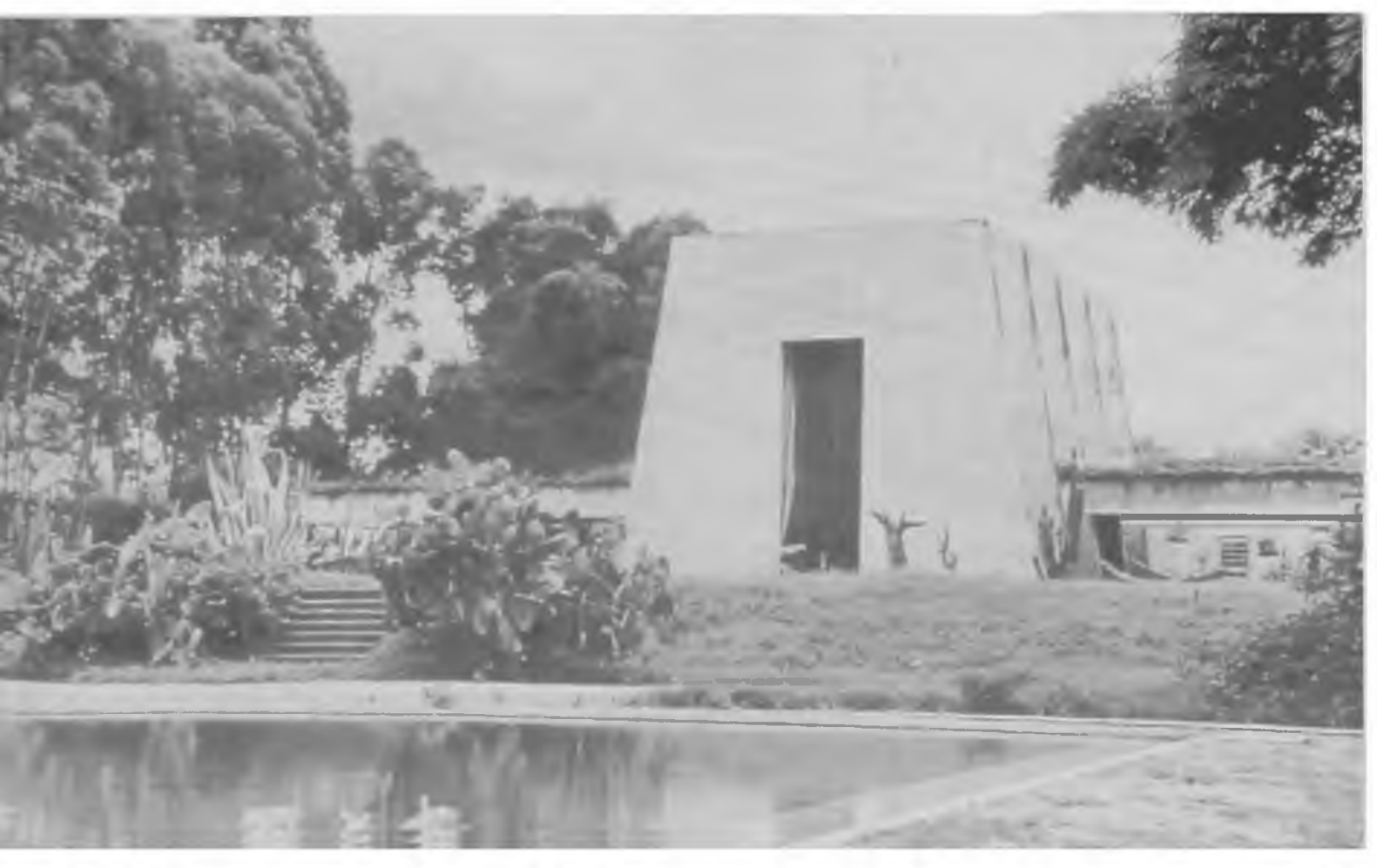


Figura 2 - Casa sem dono ne 3, projeto de Lúcio

Costa, 1932-36

Fonte: COSTA, 1995, p. 89 


\section{Primeiros Paisagistas}

Não resta dúvida que o empenho dos arquitetos foi decisivo para o fortalecimento do papel do paisagismo e a redefinição dos conteúdos da disciplina no Brasil, como nunca antes havia sido possível. Por outro lado, criou condições favoráveis para que surgissem paisagistas comprometidos com as causas modernas - caso de Mina Klabin Warchavchik e Roberto Burle Marx.

Incentivada pelo arquiteto e esposo Gregori Warchavchik, Mina K. Warchavchik realizou grande parte dos espaços externos das oito residências por ele projetadas em São Paulo. Perseguia uma economia de meios na organização dos ambientes ajardinados, sintonizada com o mesmo despojamento e purismo formal das arquiteturas. Dispunha como estratégia recorrente poucas massas vegetais envolvendo os volumes arquitetônicos, em meio a gramados extensivos, quando possíveis, balizados também por alguns caminhos de pedras, resultando em composições que se afastavam da característica profusão de elementos do jardim eclético de fins dos séculos 19 e início do 20 no Brasil. Em contraposição ao emprego dominante de plantas exóticas na definição dos jardins residenciais na época, a paisagista buscou valorizar as essências nacionais, especialmente algumas cactáceas. Como a pintora Tarsila do Amaral e outros artistas modernos, Mina K. Warchavchik se valia dos cactos como indutores de um novo olhar sobre a paisagem brasileira, transformando-os em ícones de modernidade e brasilidade. Dispunha-os com freqüência em pontos destacados ou em grupos de marcante presença nos jardins.

Essa linha de experimentação foi iniciada em sua própria residência na rua Santa Cruz, em 1928; prosseguiu na realização dos jardins da casa da rua ltápolis, em 1929; e teve seu ponto alto na obra da rua Bahia, em 1930.

Dois anos depois, foi a vez de Roberto Burle Marx principiar na busca pelo moderno, em uma obra também de natureza privada: as áreas externas da residência de Alfredo Schwartz, no Rio de Janeiro. Era uma solução que se baseava em procedimentos similares aos de Mina K. Warchavchik: o essencialismo dominava o lançamento dos grupos de vegetação e dos pisos, de caráter bem mais bidimensional que tridimensional, como nas pesquisas do cubismo e purismo. 


\section{Apoio do Estado}

As décadas de 10 e 20 haviam assistido às primeiras ações do nascente movimento moderno brasileiro, que se insurgia contra $o$ modelo sociocultural vigente baseado no passadismo e no estrangeirismo, recebendo guarida apenas nos salōes mais progressistas das elites econômicas e intelectuais. Os tempos seguintes presenciaram a revisão e a ampliação desses objetivos, com o despontar da intenção de levar as causas modernas ao conjunto da sociedade, transcendendo as discussões restritas aos saraus culturais. A modernidade buscava se efetivar como um fenômeno público, inserindo-se completamente no cotidiano da população.

Maria Cecília França Lourenço (1995, p. 19) avalia o alcance dessa atitude, ressaltando que somente a partir desse momento,

o moderno brasileiro assume uma feição de projeto, muito mais do que sua primeira forma, ligada à finalização de um produto notável e modernista. Agora, o projeto, ou seja, a formulação de um conjunto propiciador do salto, tem como partido criar sistemas públicos de difusão, preservação e ensino, bem como atualizar o viver, inserindo o moderno no cotidiano, numa grande diversidade de vertentes. Englobam desde o sistema artístico-cultural, o político sintonizado com as esquerdas, até o industrial tentando concretizar seus sonhos.

Nesse empenho de trazer o moderno para a cidade e o cotidiano, os espaços de vivência pública, principalmente as praças, os jardins e os parques, configuravam um âmbito privilegiado e sua viabilização se tornava possível pela entrada em cena de um novo agente incentivador da modernidade - o Estado.

A produção arquitetônica e paisagística moderna havia encontrado um respaldo titubeante na iniciativa privada até a década de 20 . No entanto, nas duas décadas seguintes, o quadro que se delineava já era bem diferente. As ações do movimento moderno passavam a contar com um decisivo apoio governamental, como se deu no Recife, em 1935. 


\section{Vanguarda no Recife}

Desde a Revolução de 1930, o clima político-social no país estava em ebulição. O governo provisório getulista vinha se desenvolvendo em meio a revoltas armadas, greves operárias de vários setores, confrontos entre radicais de direita e esquerda (integralistas e comunistas) e constantes manifestações da população pró e contra o fascismo na capital federal e nas principais cidades do país.

Em 1934, dois fatos políticos pareciam apontar uma certa volta à normalidade: a promulgação da nova constituição e Vargas assumindo a Presidência da República por meio de votação indireta da Assembléia Nacional Constituinte, comprometendo-se a restabelecer o processo democrático com eleições diretas em 1938.

Naquele ano de 1934, Carlos de Lima Cavalcanti, então interventor de Pernambuco, lançava uma ação de incentivo à arquitetura, paisagismo e urbanismo modernos no estado, posteriormente reconhecida entre as pioneiras empreendidas pela esfera pública. Cavalcanti promoveu a criação de um departamento de construções e intervenções urbanas, retirando essa atribuição da Secretaria de Viação e Obras Públicas do Estado, que passaria então a responder apenas pelas vias e estradas [Baltar, 1998]. Nascia a Diretoria de Arquitetura e Construção, com plenos poderes para renovar os equipamentos e espaços públicos segundo as pautas do movimento moderno, atendendo às demandas da capital e das cidades do interior (Baltar, s/d, p. 14).

Para organizar essa repartição, o governante convidou dois jovens do círculo arquitetônico moderno do Rio de Janeiro: Luiz Nunes e Roberto Burle Marx. Nunes foi encarregado da coordenação geral da divisão, e Burle Marx do comando de uma subseção de parques e jardins (Baltar, 1998). No ano seguinte, foi a vez de Attílio Correia Lima, também do grupo de modernos cariocas, ser chamado pelo interventor para estudar um novo plano urbano para Recife (Outtes, 1997, p. 129). Cavalcanti buscava se cercar da elite de profissionais comprometida com a modernidade, tencionando fomentar ações para dinamizar um estado que concentrava o quinto maior contingente populacional do país e se transformava, paulatinamente, na região mais industrializada do Nordeste brasileiro.

Em fins de 1935, os esforços da diretoria na implementação de novas metodologias de racionalização projetual e construtiva, até então desconhecidas na esfera da administração pública local, começavam a dar bons frutos em duas arquiteturas no Recife. O Hospital da 
Polícia Militar e o pavilhão do Leprosário da Mirueira faziam um uso experimental e inventivo de uma tecnologia inusual na região - o concreto armado-, combinado ao resgate de elementos construtivos tradicionais: os elementos vazados (Silva, 1988, p. 21-22).

Quando se colhiam os primeiros resultados, os trabalhos foram bruscamente interrompidos. Com a tentativa de golpe comunista em novembro daquele ano, o interventor foi afastado sob acusação de apoiar os agitadores. E a diretoria acabou fechada. Desvencilhandose do problema, Cavalcanti retomou o cargo em 1936 e tratou de reunir novamente a equipe de arquitetos para reativar o órgão de planejamento, que passou a se denominar Diretoria de Arquitetura e Urbanismo (Baltar, s/d, p. 14).

Projeto inovador dessa segunda fase foi a Escola Alberto Torres, cujo ingresso se fazia por passarelas "atirantadas" em arcos de concreto armado, em uma ousadia para a época, ensaiada por Joaquim Cardoso, que tempos depois se notabilizou como talentoso calculista da obra de Oscar Niemeyer [Silva, 1988, p. 22]. As atividades do departamento se prolongaram até fins de 1937, quando foram encerradas definitivamente por novos fatos políticos. Dessa vez, pela negação real do interventor em apoiar o gol pe varguista, que instaurou o Estado Novo.

\section{Ações de Burle Marx}

À frente do setor de parques e jardins, Roberto Burle Marx lançou um programa de requalificação e implementação de espaços públicos para o Recife. Este programa envolveu a reforma de algumas das principais áreas de lazer e convívio coletivo existentes na cidade e de novas estruturas.

Ao longo de pouco mais de três anos, o paisagista desenvolveu propostas para: o jardim da Casa Forte, as praças Euclides da Cunha (Cactário da Madalena), Arthur Oscar, Maciel Pinheiro, Pinto Damaso, da República, do Entroncamento, Chora Menino, Barão de Lucena e a praça XVII, os parques do Derby, Dois Irmãos, Amorim, os largos da Paz e das Cinco Pontas (Cavalcanti, 1936, p. 143-4). As duas primeiras eram novas áreas; as demais, reformas de espaços existentes, encaminhadas mediante um redesenho mais ou menos radical de canteiros, pisos e caminhos, além da introdução ou da reposição de espécies vegetais. Com o segundo e definitivo afastamento de Burle Marx, os quatro últimos projetos não foram provavelmente levados adiante. 
Figuras 6 e 7 - Praça Arthur Oscar: Projeto executivo e fotografia de época Fonte: Acervos Escritório Burle Marx \& Cia. e Gilda Pina
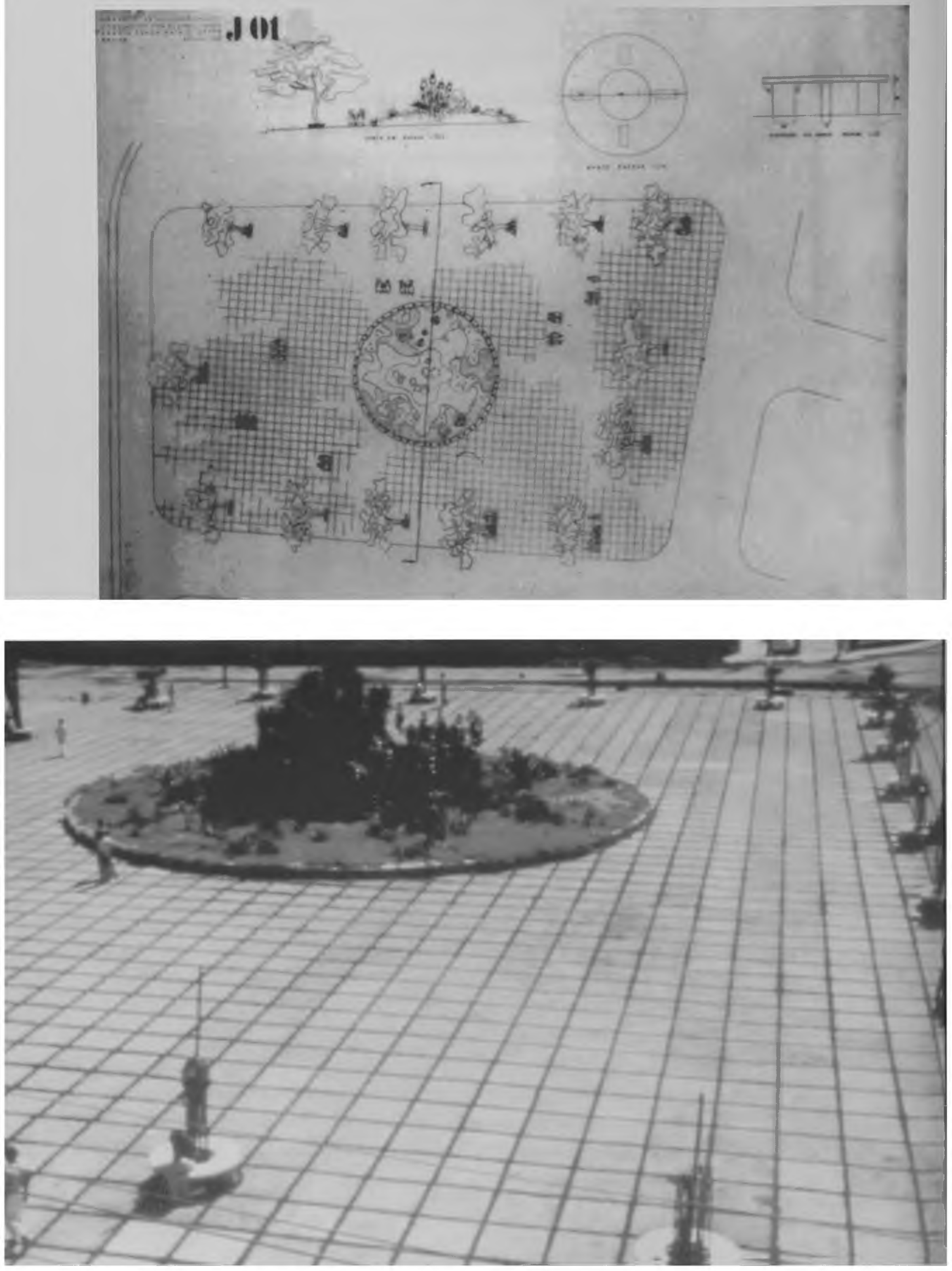
Nesse conjunto de obras, o paisagista buscava ampliar uma reflexão sobre os conteúdos modernos que as áreas verdes urbanas passariam a contemplar, ressaltando quatro dimensões principais: a recreativa, a artística, a educativa e a ambiental. Antevia a crescente importância que as praças, os jardins e os parques assumiriam daí por diante em uma cidade transformada, principalmente, pela verticalização das construções para atender a maiores contingentes populacionais, pela diminuição de espaços de recreação privados e pelos efeitos danosos da industrialização na qualidade ambiental, deixando-se influenciar pelo discurso urbano de Le Corbusier.

Burle Marx tinha convicções claras sobre o papel que caberia ao paisagismo moderno, principalmente, o potencial transformador do mesmo na geração de melhores condições de vida pela criação de espaços verdes públicos. Em um artigo publicado pelo jornal recifense Diário da Manhã, de 22 de junho de 1935, escrevia:

"O jardim moderno representa nas grandes cidades um verdadeiro pulmão coletivo. É nele que o habitante urbano vem respirar um pouco de ar puro, cansado da luta diária nos escritórios acanhados, nas ruas asfaltadas, nos ambientes fabris.

É nele que as crianças moradoras de apartamentos empoleirados, casa de quintais reduzidos ou habitações coletivas poderão encontrar um meio amplo para seus brinquedos, recebendo para suas trocas orgânicas um ar desprovido de contaminação. [...]

Já é fato conhecido o papel que representa a arborização e ajardinamento das cidades quanto à modificação de suas condições meteorológicas. [...]

Sob o ponto de vista educacional, o jardim moderno tem como objetivo trazer para o habitante da cidade um pouco de amor pela natureza, fornecer-lhe meios para que possa distinguir sua própria flora da exótica $[\ldots]^{\prime \prime}$. 


\section{Jardins Aquáticos}

Entre as proposições mais representativas figurava o Jardim da Casa Forte. Era uma das primeiras alternativas pragmáticas e programáticas aos excessos do jardim público eclético, sem romper completamente os princípios acadêmicos da simetria, dos eixos compositivos e das perspectivas axiais, mas abandonando a adoção dos parterres e das práticas topiárias.

No mesmo texto veiculado pelo Diário da Manhã, de 22 de junho de 1935, Burle Marx expunha detalhadamente à comunidade local suas intenções para a Casa Forte:

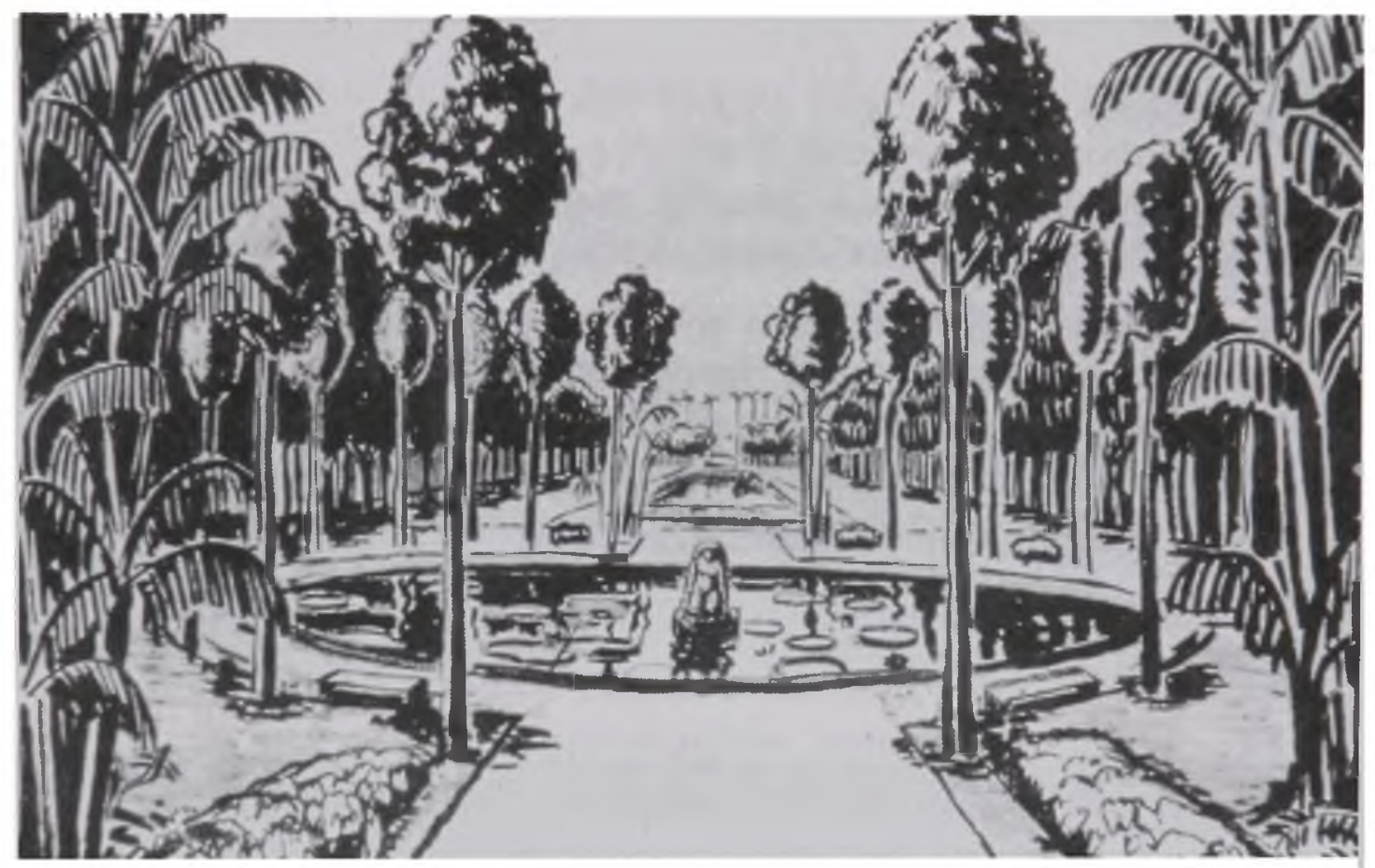

Figuras 8 e 9 - Jardim da Casa Forte: Perspectiva de estudo e registro fotográfico original Fonte: Acervos Escritório Burle Marx \& Cia. e Museu do Cidade do Recife

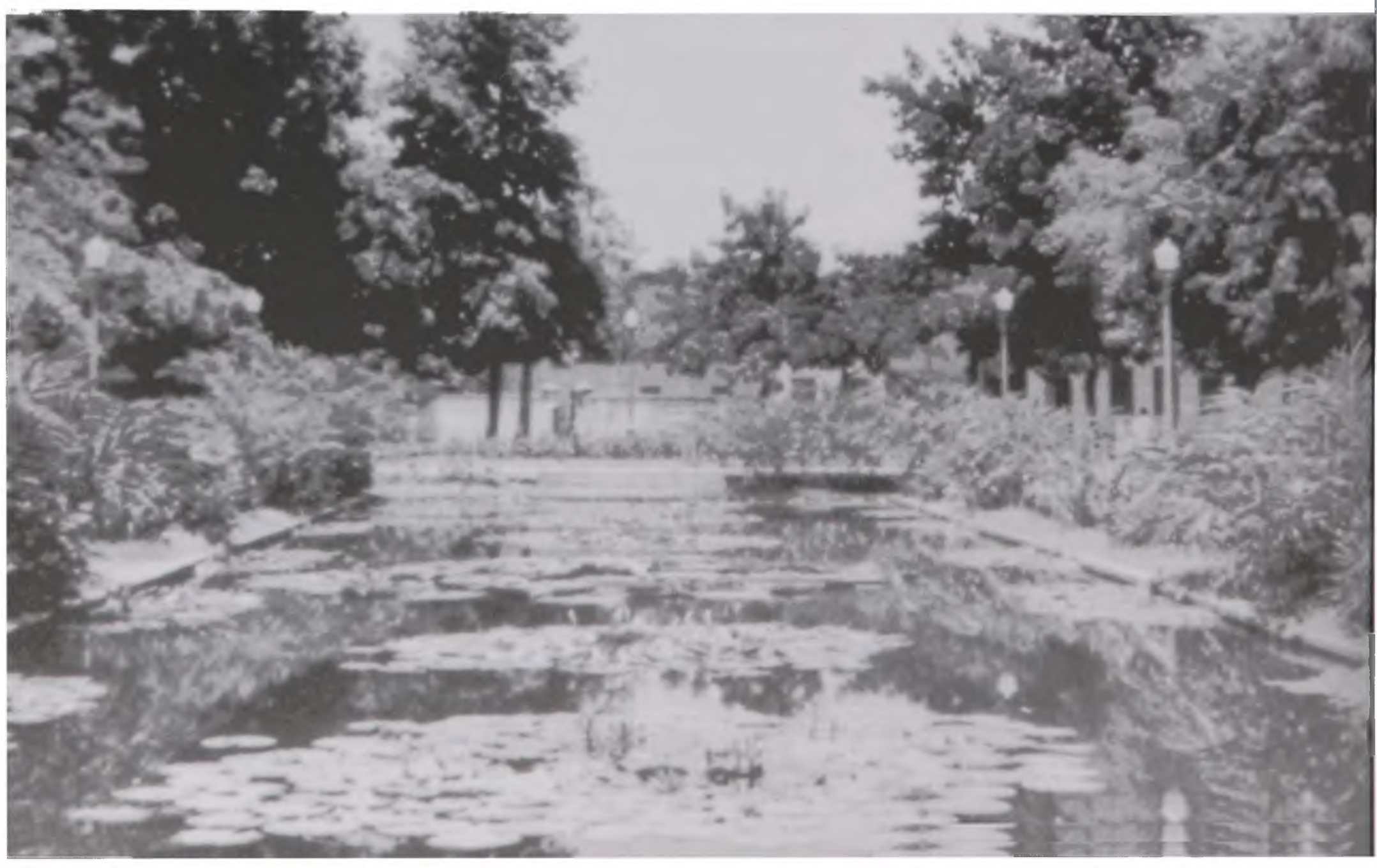


"O jardim será composto de três lagos, obedecendo a formas geométricas de maior simplicidade. Como função educativa, cada um deles representará um grupo isolado pela proveniência geográfica dos seus elementos, subordinados à idéia de conjunto.

O lago central circular será o recipiente da flora aquática amazônica. No centro desse lago, será colocada uma estátua de Celso Antonio, representando uma índia a se banhar. Circundando o lago, haverá uma fileira de paus-mulatos, árvore interessante pelo seu feitio com troncos em colunata e copas simétricas, de grande efeito para jardins arquitetônicos. Ao lado das entradas para passeio que envolvem o lago, serão vistos canteiros de tinhorōes, que darão a nota colorida ao local. Nos quatro ângulos, existirão blocos de palmeiras amazônicas, tais como: scheellias, assais, mumbacas, bacabas, urucuris, jouaris etc.

Quanto aos dois lagos retangulares, um será dedicado à flora americana, e o outro, à exótica. No primeiro, achar-se-á toda a grande variedade de plantas aquáticas dos nossos rios e açudes. Ao redor do lago, plantas marginais, como as aningas, da família das aráceas, os célebres tajás, do Amazonas, com suas folhas de coloridos os mais diversos; alguns representantes da família das gramíneas etc., fornecerão um aspecto de exuberância tropical. Caminhando de dentro para fora, encontraremos um gramado e um passeio. Finalmente, duas carreiras de árvores, tais como: ipê, jatairana, mulungu, munguba etc.

O lago exótico conterá a flora aquática das regiões tropicais dos outros continentes. Nele serão vistos os lótus, planta aquática oriunda do Nilo, que teve grande cultivo na Índia. Serão vistos também os cyperus papirus, gênero igualmente egípcio. Entre as espécies marginais, encontraremos espécies de grande beleza, como: a canna indica, a salla aethiopica, o crinum powell, a strelitzia e algumas musáceas decorativas. Entre as zinziberáceas de grande porte, plantaremos o bastão-do-imperador. Entre as árvores que ladeiam este lago, figurarão: o pão-teka, os flamboyants de floração rubra e amarela, acácias diversas etc." 


\section{Estratégias e Métodos}

As soluções compositivas que o paisagista lançava para os novos jardins derivavam de um mesmo conjunto de estratégias, embora os resultados fossem completamente distintos em todos os casos. Tratava-se de configurar espaços centrípetos, ou seja, definidos a partir de uma hierarquia de elementos de interesse, que progressivamente conduzissem à atenção dos observadores da periferia ao centro dos ambientes. Manipulando contrastes acentuados de luz e sombra e de escalas das massas vegetais, Burle Marx dispunha aléias de árvores no perímetro, criando zonas sombreadas para descanso e permanência, e iluminava as áreas centrais para ressaltar conjuntos vegetais com herbáceas e arbustivas.

Ao que tudo indica, testou primeiro esse partido na polêmica praça Euclides da Cunha, envolvendo os espaços com linhas de árvores típicas do Nordeste, como umbuzeiros, joazeiros, paus-d'arco, e destacando como que uma ilha conformada por gêneros brasileiros de cactáceas e por espécies de euforbiáceas e bromeliáceas, afora a pontuação de um escultura de um sertanejo, Celso Antonio, que não chegou a ser realizada (Burle Marx, 1935B). Depois aplicou essa solução nas praças Casa Forte, Arthur Oscar e Barão de Lucena.

Na série de encargos do Recife, Burle Marx buscou pôr em prática algumas substanciais alterações na metodologia de trabalho paisagístico então consolidadas no país, enfatizando a importância da fase inicial de prefiguração espacial, por meio de um conjunto de peças projetuais mais detalhadas - planos acompanhados da especificação vegetal, cortes e perspectivas. O paisagista perseguia uma distinção mais clara, embora organicamente relacionada, entre as etapas conceitual e prática da obra paisagística, afirmando o papel fundamental do desenvolvimento do projeto. Vale lembrar que até os anos 30, os espaços verdes eram resolvidos bem mais durante a própria execução, seguindo, em poucos e excepcionais casos, planos genéricos previamente riscados. Provavelmente, Burle Marx introduzia essas mudanças nos procedimentos de trabalho sob a influência do que se operava em arquitetura, com a sistematização racional e a padronização das etapas de projeto, desde os estudos iniciais até o detalhamento completo, empreendidas pelos arquitetos modernos.

Levar adiante o programa de reforma e execução das áreas verdes na cidade não foi uma tarefa isenta de problemas e dificuldades. Talvez nada tenha exigido mais empenho que a obtenção dos espécimes 


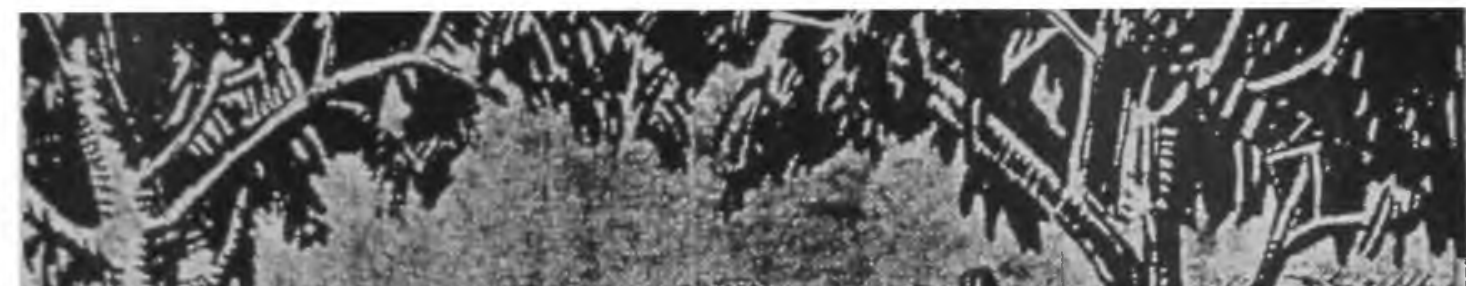

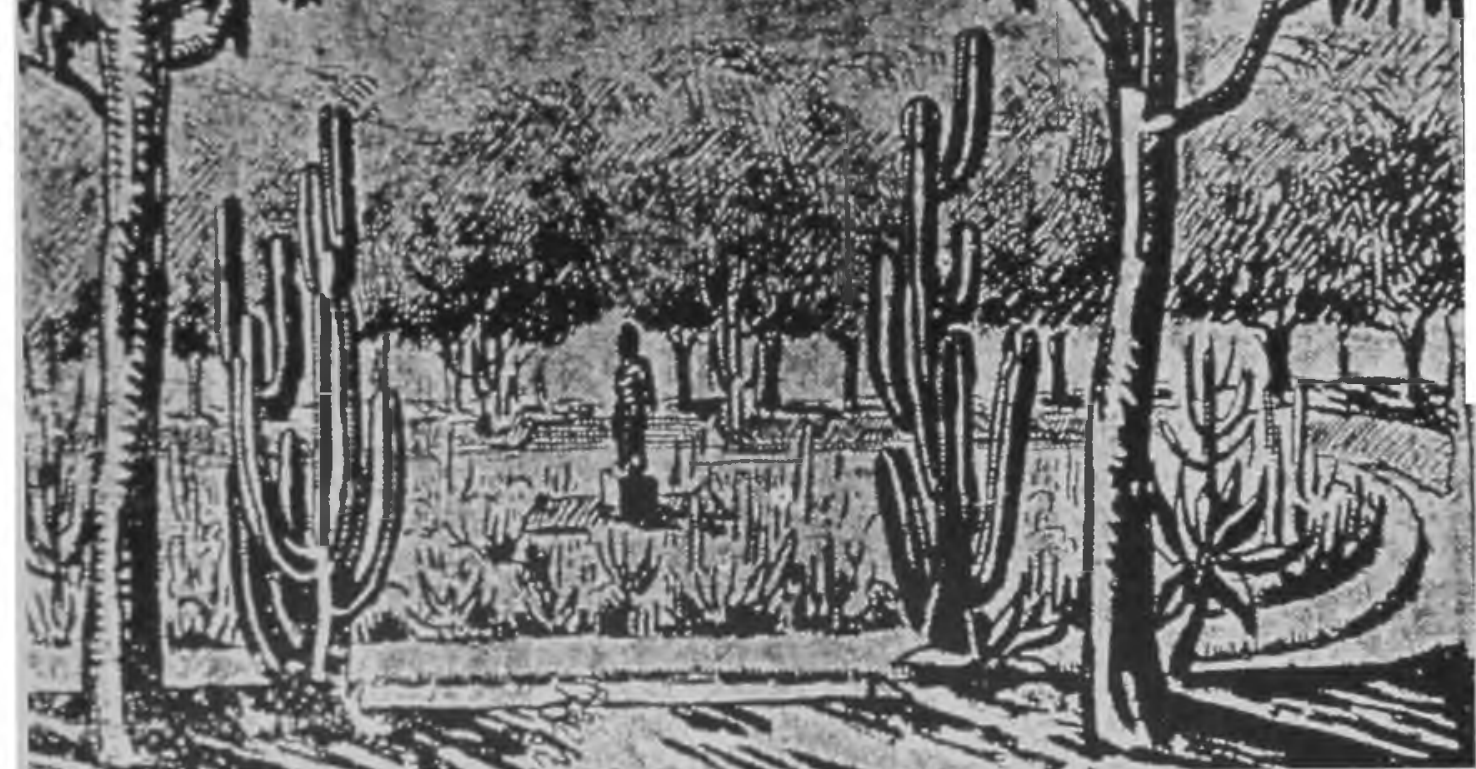

Figura 10 e 11 - Praça

Euclides da Cunha:

Perspectiva de estudo e

fotografia do final

dos anos 30

Fonte: Burle Marx, 1935B,

e Acervo Museu da

Cidade do Recife




vegetais, em uma localidade carente de uma rede consolidada de fornecedores de plantas ornamentais - aliás, como todas as demais regiões do país na ocasião. Burle Marx se valeu de três procedimentos: a coleta direta nos ambientes naturais das cercanias do Recife, a aquisição de exemplares no Jardim Botânico do Rio de Janeiro e a importação de mudas da Alemanha.

A maioria das cactáceas da praça Euclides da Cunha foram colhidas na região. Da instituição carioca, vieram os paus-mulatos para o Jardim da Casa Forte e um conjunto de 70 palmeiras para o parque do Derby. Da Alemanha, zínias para a praça da República e para o jardim interno do palácio do governador que, juntamente com espaços externos, estavam sendo remodelados pelo paisagista (Cavalcanti, 1936, p. 144; A reforma dos jardins do Recife, 1937).

O trabalho no Recife não apenas deixou marcas profundas na trajetória de Burle Marx, mas acabou por se configurar como marco inaugural do moderno espaço público no Brasil.

\section{Bibliografia}

BALTAR, Antônio Bezerra. Episódio pioneiro da arquitetura moderna em Pernambuco. Revista da Escola de Belas Artes, Recife, n.1, p. 13-8, s/d. . Entrevista realizada por Guilherme Mazza Dourado em 14/5/1998.

BURLE MARX, Roberto. Jardim da Casa Forte. Diário da Manhã, Recife, 22 jun. 1935.

. Jardins e Parques do Recife. Diário da Tarde, Recife, 14 mar. 1935B.

CAVALCANTI, Carlos de Lima. Relatório Apresentado pelo governador Carlos de Cavalcanti à Assembléia Legislativa de Pernambuco a 1 으 de agosto de 1936. Recife: Imprensa Oficial, 1936.

COSTA, Lúcio. Registro de uma vivência. São Paulo: Empresa das Artes, 1995.

DIÁRIO DE PERNAMBUCO. A reforma dos jardins do Recife. Recife, 20 maio 1937.

FERRAZ, Geraldo. Warchavchik e a introdução da arquitetura moderna no Brasil: 1925 a 1940. São Paulo: Museu de Arte de São Paulo, 1965.

LOURENÇO, Maria Cecília França. Operários da modernidade. São Paulo: Hucitec/Edusp, 1995.

MATTAR, Denise. Flávio de Carvalho: 100 anos de um revolucionário romântico. Rio de Janeiro: Centro Cultural do Banco do Brasil, 1999.

OUTTES, Joel. O Recife: Gênese do urbanismo 1927-1943. Recife: Editora Massangana/ Fundação Joaquim Nabuco, 1997.

SILVA, Geraldo Gomes da. Marcos da arquitetura moderna em Pernambuco. In: SEGAWA, Hugo (Org.). Arquiteturas no Brasil/ Anos 80. São Paulo: Projeto, 1988, p. 19-27. 